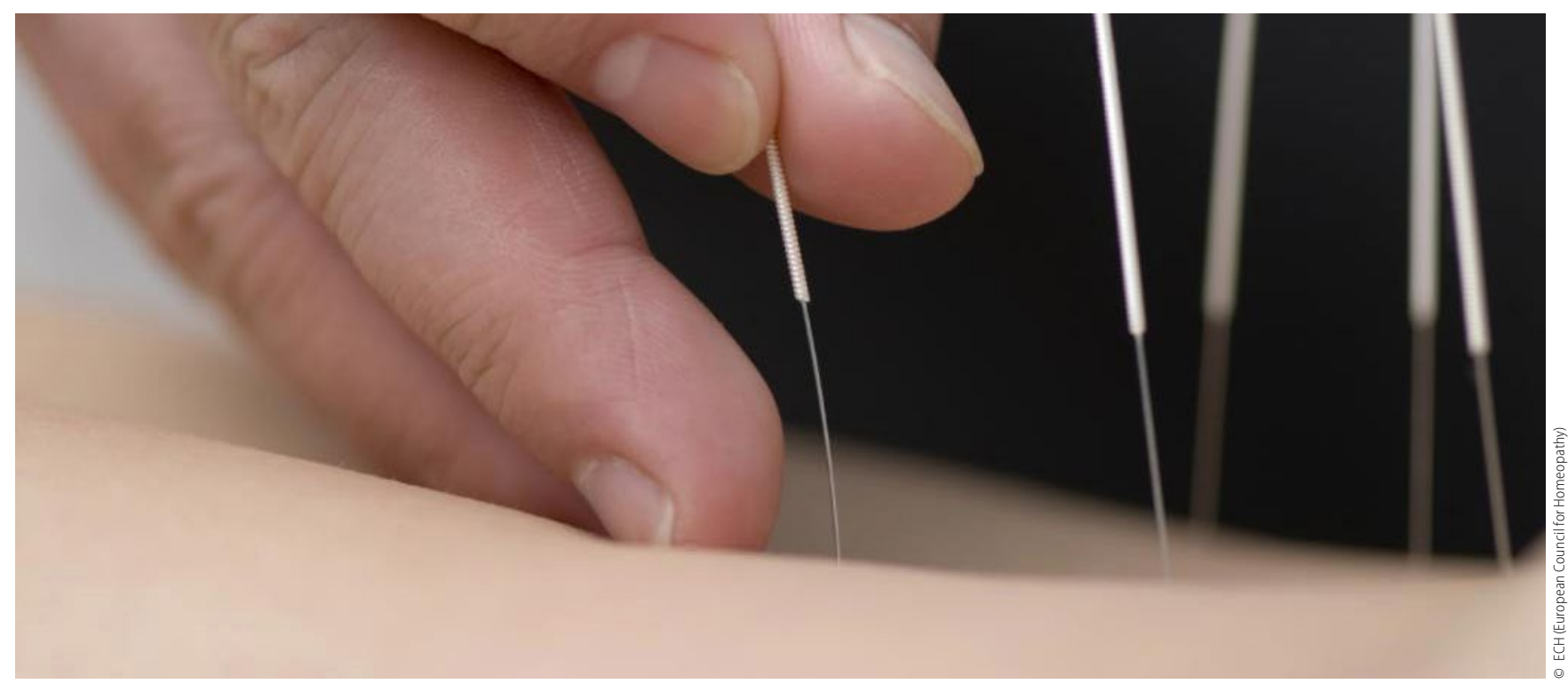

Alternative Therapieform in der Zahnmedizin

\title{
Anwendungsgebiete der Akupunktur
}

\begin{abstract}
Akupunktur bezeichnet die Behandlung durch Nadelstiche, wie sie in der traditionellen chinesischen Medizin zur Stimulation spezifischer Triggerpunkte angewandt wird. Neben Nadeln kommen dort aber auch andere Techniken, wie elektrische Impulse, magnetische Energie, Licht oder akustische Signale zum Einsatz. Auch in der Zahnmedizin ist Akupunktur anwendbar.
\end{abstract}

Seit 2500 Jahren bekannt, haben sich neben der Nadelakupunktur auch die Moxibustion, die Fotoakupunktur, die Elektroakupunktur, die Akupressur und die Mikrosystemakupunktur entwickelt. 1979 hat die Weltgesundheitsorganisation Symptome und Umstände beschrieben, die per Akupunktur gelindert werden können. Mehrere klinische Studien weisen die Linderung postoperativer Schmerzen durch Akupunktur nach. Darin sei die Akupunktur dem Placeboeffekt überlegen gewesen.

Akupunktur scheint als alternative Behandlungstechnik auf die Zahnmedizin anwendbar zu sein, insbesondere wenn chronische Krankheitsbilder wie der myofaziale Schmerz oder Kiefergelenkschmerz zu behandeln sind.

Bei klinischen, randomisierten, kontrollierten Studien konnte in 73 Prozent der Fälle ein positiver Effekt der Akupunktur auf chronische Schmerzzustände beschrieben werden. Die Akupunktur könnte daher eine sinnvolle Ergänzung zur konventionellen Schmerztherapie darstellen.

\section{Bei Zahnarztphobie und zur Schmerzlinderung}

Zudem wurde die Akupunktur erfolgreich bei der Behandlung des Würgereizes, der Zahnarztphobie und der postoperativen
Schmerzlinderung eingesetzt. Als Wirkmechanismus kommt die Freisetzung von Neuromediatoren im Rückenmark und die Inhibition prä- und postsynaptischer Neuronen im Tractus spinothalamicus in Betracht. Die Stimulation des Hypothalamus und der Hypophyse führt zudem zur Freisetzung von adrenokortikotropen Hormonen und beta-Endorphinen. Zur Behandlung der Zahnarztphobie könnte die Modulation des limbischen-paralimbischen-neokortikalen neuronalen Netzes von Bedeutung sein.

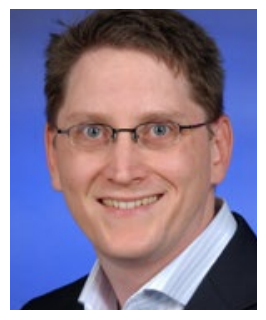

Prof. Dr. Dr. Felix P. Koch

Autor des Wissenschaftlichen Infodienstes, Lehrbeauftragter der Uniklinik Frankfurt, Praxisklinik für Mund- , Kiefer- und plastische Gesichtschirurgie in Wiesbaden. 